Pure Appl. Chem., Vol. 84, No. 3, pp. 473-484, 2012.

http://dx.doi.org/10.1351/PAC-CON-11-07-15

(C) 2012 IUPAC, Publication date (Web): 6 January 2012

\title{
Phosgene-free synthesis of 1,3-diphenylurea via catalyzed reductive carbonylation of nitrobenzene*
}

\author{
Andrea Vavasori ${ }^{\ddagger}$ and Lucio Ronchin \\ Department of Molecular Sciences and Nanosystems, Ca' Foscari University of \\ Venice, Dorsoduro 2137, 30123 Venice, Italy
}

\begin{abstract}
Diphenylurea (DPU) has been proposed as a synthetic intermediate for phosgene-free synthesis of methyl $N$-phenylcarbamate and phenyl isocyanate, which are easily obtained from the urea by reaction with methanol. Such an alternative route to synthesis of carbamates and isocyanates necessitates an improved phosgene-free synthesis of the corresponding urea. In this work, it is reported that $\mathrm{Pd}(\mathrm{II})$-diphosphine catalyzed reductive carbonylation of nitrobenzene in acetic acid $(\mathrm{AcOH})$-methanol proceeds in high yield and selectivity as a one-step synthesis of DPU. We have found that the catalytic activity and selectivity of this process depends on solvent composition and on the bite angle of the diphosphine ligands. Under optimum reaction conditions, yields in excess of 90 molar \% and near-quantitative selectivity can be achieved.
\end{abstract}

Keywords: carbonylation; 1,3-diphenylurea; phosgene-free; palladium catalysis; sustainable chemistry.

\section{INTRODUCTION}

1,3-Diphenylurea (DPU) is seeing growing interest in the field of chemical technology. Ureas are a very important class of carbonyl compounds which find extensive application as agrochemicals, dyes for cellulose fibers, antioxidants in gasoline, resin precursors, and pharmaceuticals [1-8].

Moreover, DPU has been extensively studied for application as synthetic intermediates especially for the production of carbamates and isocyanates [9-22], whose importance both in industrial and academic fields is well known. Traditionally, aromatic isocyanates and carbamates are prepared on a commercial scale from aromatic nitro compounds, which are first catalytically hydrogenated to the corresponding amine. A subsequent reaction with phosgene yields the desired aromatic isocyanates. A reaction between the isocyanate and an alcohol finally affords the aromatic carbamate. However, the major disadvantages of the current commercial production processes are the use of phosgene as a raw material and the production of large amounts of $\mathrm{HCl}$ as byproduct [23,24].

It is thus natural that a great deal of research has been directed toward alternative routes to isocyanates without using phosgene. The catalytic reductive carbonylation of the aromatic nitro compounds appears to be a convenient alternative phosgene-free route. In this process the nitro group reacts directly with $\mathrm{CO}$ under the influence of a catalyst to form isocyanate or, in the presence of an alcohol, the derived carbamate (Scheme 1) [25-30].

\footnotetext{
*Pure Appl. Chem. 84, 411-860 (2012). A collection of invited papers for the IUPAC project 2008-016-1-300 "Chlorine-free Synthesis for Green Chemistry".

¥Corresponding author: Tel.: +39 041 2348577; Fax: +39 041 2348517; E-mail: vavasori@unive.it
} 


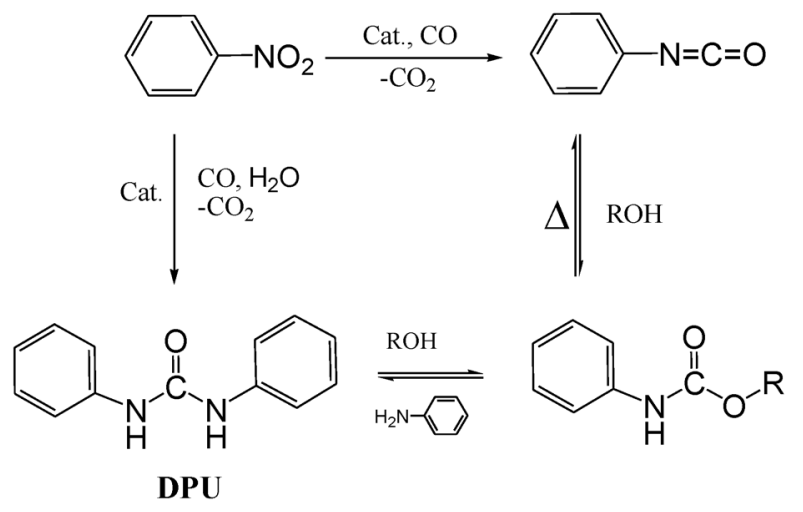

Scheme 1 Reductive carbonylation of nitrobenzene to DPU, phenylisocianate, and alkyl, $N$-phenylcarbamate.

Carbamates can also be produced by the reaction of DPU with a primary alcohol [31,32], which is therefore considered as alternative route for the phosgene-free synthesis of isocyanate (obtained by thermal degradation of the alkyl, $N$-phenyl carbamate, Scheme 1).

Obviously, since 1,3-disubstituted ureas are usually prepared by stoichiometric reactions of isocyanates or phosgene with amines [27-32], such a reaction offers scope as an alternative to the phosgene route if new efficient, selective, and environmentally friendly protocols for the ureas preparation are developed, able to supplant the classical syntheses [33-40].

Numerous methods of phosgene-free synthesis for DPU have been reported in the literature. More promising routes for a large-scale production involve the catalytic oxidative carbonylation of aniline and the reductive carbonylation of nitro compounds [27-30].

The catalyst that is required for the reaction of the nitro substrate with $\mathrm{CO}$ is often based on a group 8-10 metal [41], though a lot of research has been done in the past on catalysts based upon sulfur, selenium, or tellurium. Among metal-based catalyst systems, the mechanistic insight into those of ruthenium is especially well understood. Catalysts based on palladium, however, have been found to give the highest activity and selectivity, and detailed studies are reported for both homogeneous and heterogeneous systems [42-51].

Among the syntheses proposed in literature, the reductive carbonylation of nitrobenzene, in the presence of aniline as a co-reagent, appears as one of the most promising proposals to obtain DPU with high yield and selectivity [24-30,45,50,51]. Among the catalyst precursors based on palladium, the $\mathrm{Pd}(\mathrm{II})$-phenanthroline complexes appear more efficient with respect to the Pd(II)-diphosphine [26]. The influence on the catalytic activity and on the selectivity of the coordinating ligands is well discussed in many papers, with particular attention to the influence of the bite angle of the diphosphine ligands [46,47,50-53]. Although these authors already claimed the positive effect on the catalytic activity of the acid promoter (e.g., acetic acid, $\mathrm{AcOH}$ ), relatively little attention is devoted to the possible influence on the selectivity of such an acid [46,50-53]. Following our previous studies regarding the influence on the $\mathrm{Pd}(\mathrm{II})$ activity of $\mathrm{AcOH}$ [54-56], we decided to employ this cosolvent also in the reductive carbonylation.

In this work we focus on the phosgene-free synthesis of DPU, via the Pd(II)-diphosphine-catalyzed reductive carbonylation of nitrobenzene carried out in a mixture of acid acetic-methanol, in the absence of aniline.

Particular attention has been paid to study the influence of the solvent composition as well as of the bite angle of the chelating ligands combined with the nature of the coordinating anions, on the activity and selectivity of the Pd(II) catalyst precursors. A reaction mechanism is also proposed and discussed. 


\section{EXPERIMENTAL}

\section{Reagents}

CO supplied by SIAD Company ("research grade", purity $>99.9 \%$ ). Nitrobenzene, bis(diphenylphosphino)methane (DPPM), 1,2-bis(diphenylphosphino)ethane (DPPE), 1,3-bis(diphenylphosphino)propane (DPPP), 1,4-bis(diphenylphosphino)butane (DPPB), 1,1'-bis(diphenylphosphino)ferrocene (DPPF), bis[(2-diphenylphosphino)phenyl] ether (DPEphos), 4,5-bis(diphenylphosphino)-9,9dimethylxanthene (XANTphos), $p$-toluenesulfonic acid (TsOH), AcOH, and methanol, were Aldrich products.

The complexes $\left[\mathrm{PdX} \mathrm{X}_{2}(\mathrm{P}-\mathrm{P})\right](\mathrm{X}=\mathrm{Cl}$, TsO, AcO; $\mathrm{P}-\mathrm{P}$, see Table 1$)$, were prepared by following the procedure reported in literature [57-59]. The crystalline compounds obtained after re-crystallization were characterized by IR and multinuclear NMR spectroscopy.

Table 1 The diphosphine chelating ligands used and the corresponding natural bite angle.<smiles>c1ccc(P(CP(c2ccccc2)c2ccccc2)c2ccccc2)cc1</smiles>

DPPM<smiles>c1ccc(P(CCCP(c2ccccc2)c2ccccc2)c2ccccc2)cc1</smiles>

DPPE<smiles>c1ccc(P(CCCCP(c2ccccc2)c2ccccc2)c2ccccc2)cc1</smiles>

DPPP<smiles>c1ccc(P(CCCCCP(c2ccccc2)c2ccccc2)c2ccccc2)cc1</smiles>

DPPB
Bite Angle $\left({ }^{\circ}\right)$

67.2

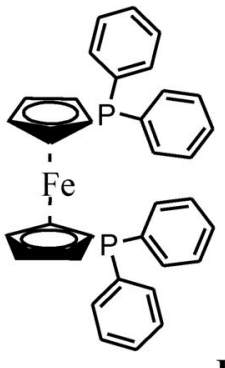

DPPF

99.1

78.1<smiles>c1ccc(P(c2ccccc2)c2ccccc2Oc2ccccc2P(c2ccccc2)c2ccccc2)cc1</smiles>

DPEphos 102.9

86.2<smiles>CC1(C)c2cccc(P(c3ccccc3)c3ccccc3)c2Oc2c(P(c3ccccc3)c3ccccc3)cccc21</smiles>

XANphos

110 


\section{Equipment}

The catalyst precursors were weighed on a Sartorius Micro balance (precision $0.001 \mathrm{mg}$ ).

Gas-chromatographic (GC) analysis of the liquid phase was performed on a Hewlett Packard Model 5890, Series II chromatograph fitted with a HP1, $30 \mathrm{~m} \times 0.35 \mu \mathrm{m} \times 0.53 \mu \mathrm{m}$ column (detector: FID; carrier gas: $\mathrm{N}_{2}, 0.2 \mathrm{ml} / \mathrm{min}$; oven: $45^{\circ} \mathrm{C}(3 \mathrm{~min})$ to $250{ }^{\circ} \mathrm{C}$ at $\left.15^{\circ} \mathrm{C} / \mathrm{min}\right)$.

GC/MS analyses of the solutions were performed on a MS Agilent apparatus 5975C Model, interfaced with an Agilent chromatograph 7890A Model equipped with a HP1 column $(30 \mathrm{~m} \times 0.25 \mu \mathrm{m} \times$ $0.25 \mu \mathrm{m}$, oven: $45^{\circ} \mathrm{C}(3 \mathrm{~min})$ to $250{ }^{\circ} \mathrm{C}$ at $\left.15{ }^{\circ} \mathrm{C} / \mathrm{min}\right)$.

High-performance liquid chromatography (HPLC) analyses were carried out by a Perkin Elmer 250 equipped with a diode array LC-235 detector and a Lichrosphere 100 (RP-18, $5 \mu \mathrm{m}$ ) column employing water acetonitrile mixtures as eluent, the concentrations of the reagent and products were calculated by calibration with standard solution.

Fourier transform infrared (FTIR) spectra were recorded on a Nicolet Magna 750 instrument in $\mathrm{KBr}$ powder.

All the NMR spectra were recorded on a Bruker Avance 300 spectrometer.

\section{Reductive carbonylation}

The catalytic reactions were carried out by using a Hastelloy C autoclave of ca. $150 \mathrm{~mL}$ provided with a magnetic stirrer. In order to avoid contamination by metallic species because of corrosion of the internal surface of the autoclave, solvent and catalyst were contained in a ca. $60-\mathrm{mL}$ Pyrex bottle, placed inside the autoclave.

The $\mathrm{CO}$ was supplied to the autoclave from a gas reservoir connected to the autoclave through a constant pressure regulator, whereas the liquid reagent was mixed with the solvent before running the reactions.

In a typical experiment, $6.8 \times 10^{-3} \mathrm{mmol}$ of catalyst precursor (e.g., $4.0 \mathrm{mg}$ of $\left[\mathrm{PdCl}_{2}(\mathrm{DPPP})\right]$ ) together with $0.50 \mathrm{mmol}$ of nitrobenzene $(61.56 \mathrm{mg})$ were added to $20 \mathrm{~mL}$ of the solvent $\left(\mathrm{CH}_{3} \mathrm{COOH}\right.$, 35 molar \% in $\mathrm{CH}_{3} \mathrm{OH}$ ), contained in the bottle placed in the autoclave. The autoclave was washed by pressurizing with $\mathrm{CO}$ (ca. $0.5 \mathrm{MPa}$ ) and then depressurizing to atmospheric pressure (this cycle was repeated 5 times, at room temperature with stirring). The autoclave was then pressurized with $0.5 \mathrm{MPa}$ of the gas mixture and then heated to $100{ }^{\circ} \mathrm{C}$ in ca. $10 \mathrm{~min}$ without stirring. The pressure was then adjusted to the desired value (typically $4.5 \mathrm{MPa}$ total pressure) and, while stirring, maintained constant throughout the experiment $(5 \mathrm{~h})$ by continuously supplying the $\mathrm{CO}$ from the reservoir. At the end of the experiment the autoclave was quickly cooled and carefully depressurized.

The solution was analyzed by HPLC, GC, and GC/MS. DPU, phenylisocyanate, aniline and methyl, $N$-phenylcarbamate were detected by GC/MS and quantified by the HPLC analysis (RP-18 column, acetonitrile/water 80:20 as eluent), because the urea thermally degrades into methyl $N$-phenylcarbamate and aniline during the injection for the GC analysis. Nitrobenzene, $N, N^{\prime}$-azo- and $N, N^{\prime}$-azoxybenzene were analyzed by GC/MS and quantified by GC technique: for the purpose of the present paper the amount of $N, N^{\prime}$-azo- and $N, N^{\prime}$-azoxybenzene were summed and reported together as molar $\%$ of $N, N^{\prime}$-azoxybenzene.

The experiments have all been conducted at least in duplicate.

\section{RESULTS AND DISCUSSION}

The precursor $\mathrm{PdCl}_{2}$ (DPPP), in methanol at $100{ }^{\circ} \mathrm{C}$ and $4.5 \mathrm{MPa}$ of $\mathrm{CO}$, gives a nitrobenzene conversion of $c a .10$ molar \%, in $5 \mathrm{~h}$ of reaction, and DPU is produced with a selectivity of ca. 1.8 molar \%.

The addition of $\mathrm{AcOH}(\mathrm{acid} / \mathrm{Pd}=50 / 1)$, enhances the catalytic activity leading to a conversion of 21 molar \% and a DPU selectivity of ca. 2.0 molar \%. Figure 1 shows that, by further increasing the 


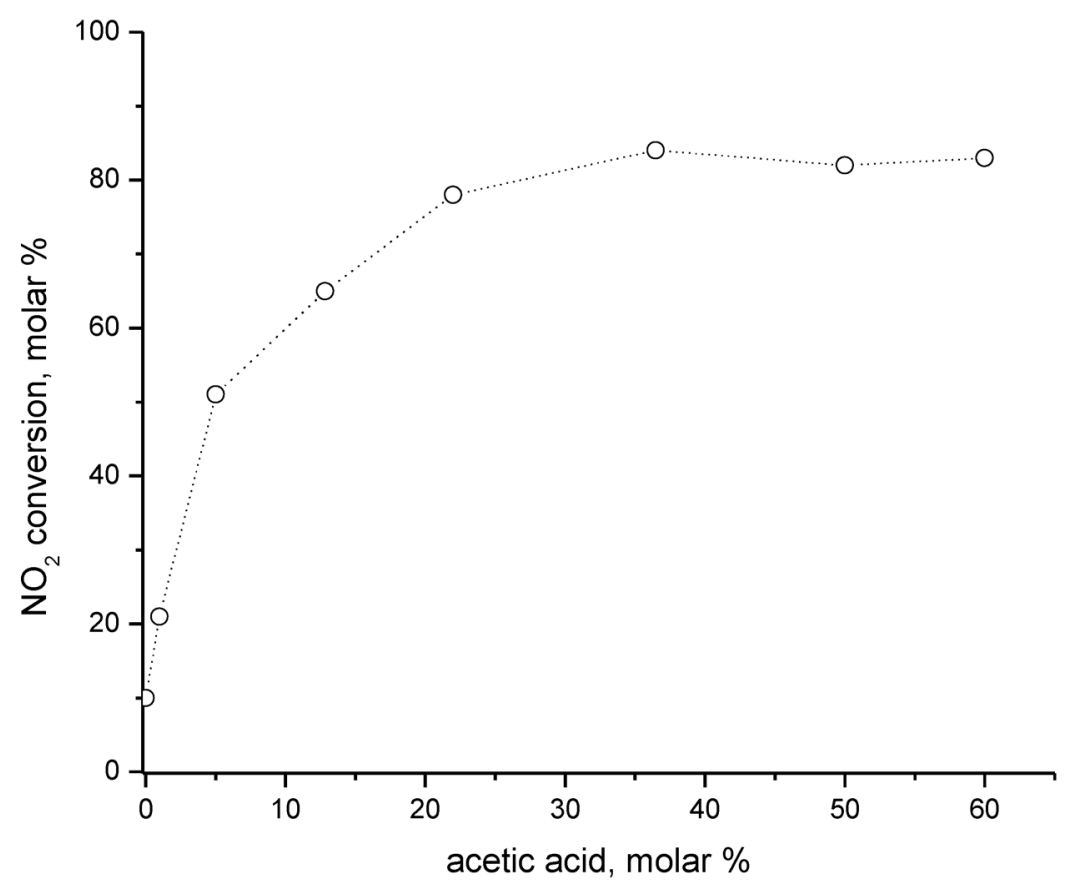

Fig. 1 Influence of the AcOH concentration on the nitrobenzene conversion. Run conditions: $\left[\mathrm{PdCl}_{2}(\mathrm{DPPP})\right]=$ $6.8 \times 10^{-3} \mathrm{mmol}(4.0 \mathrm{mg})$; nitrobenzene $=0.50 \mathrm{mmol}(61.56 \mathrm{mg})$; solvent $=20 \mathrm{~mL}(\mathrm{AcOH}+$ methanol $) ; \mathrm{CO}=$ 4.5 $\mathrm{MPa}, T=100^{\circ} \mathrm{C}$; reaction time $=5 \mathrm{~h}$.

AcOH concentration, the catalytic activity increases up to a nitrobenzene conversion of ca. 84 molar $\%$ when the acid is ca. 35 molar \%. In the range of concentration 35-60 molar \%, the conversion remains practically constant at the plateau value of ca. 84 molar \%.

The products distribution has been measured at $\mathrm{AcOH}$ concentration of 35 molar \%: the main products detected were $N, N^{\prime}$-azoxybenzene (50 molar \%) and aniline (45 molar \%), and the byproducts were phenylisocianate, methyl $N$-phenyl carbamate (trace amount), and DPU (4 molar \%).

Although the selectivity toward DPU is still poor, it appears interesting that its increase was obtained by the addition of such a large excess of acid.

The production of a large amount of aniline ( 45 molar \%) suggests the presence in solution of water, probably formed by the esterification of $\mathrm{AcOH}$ [46]. Under such experimental conditions, the usage of $\mathrm{AcOH}$ as a cosolvent could also be an advantage because it favors the formation of an efficient homogeneous reaction medium and avoids the phase separation which occurs in the presence of water and unreacted nitrobenzene. A further advantage is represented by the promoting effect of $\mathrm{AcOH}$ which avoids the formation of the inactive Pd metal responsible for the low conversion [54-57].

With the aim to increase the DPU selectivity, we have studied the influence of such solvent effects in combination with the known influences on the activity and selectivity of the P-P bite angle in the Pd(II)-(P-P) precursors [29,46-51,58].

The chelating ligands studied were the commercial diphosphines DPPM, DPPE, DPPP, DPPB, DPPF, DPEphos, and Xanphos, which are electronically very similar but with increasing bite angle (see Table 1). 


\section{Catalytic activity and selectivity of the Pd(II)-diphosphine complexes}

The Pd(II)-diphosphine complexes are prepared from the ligands in Table 1 following the procedure reported in the experimental session. The results of the carbonylations are given in Table 2.

Table 2 Catalytic activity and selectivity of the Pd(II)-diphosphine complexes.

\begin{tabular}{|c|c|c|c|c|c|c|c|}
\hline \multirow{2}{*}{$\begin{array}{l}\text { Catalyst } \\
\text { precursor }\end{array}$} & \multirow{2}{*}{$\begin{array}{c}\text { Conversion }^{\mathrm{a}} \\
\text { molar } \%\end{array}$} & \multicolumn{6}{|c|}{ Selectivity ${ }^{\mathrm{b}}$} \\
\hline & & $\begin{array}{c}\mathbf{A} \\
\text { molar } \%\end{array}$ & $\begin{array}{c}\mathbf{B} \\
\text { molar } \%\end{array}$ & $\begin{array}{c}\mathbf{C} \\
\text { molar } \%\end{array}$ & $\begin{array}{c}\text { D } \\
\text { molar } \%\end{array}$ & $\begin{array}{c}\mathbf{E} \\
\operatorname{molar} \%\end{array}$ & $\begin{array}{c}\text { DPU } \\
\text { molar \% }\end{array}$ \\
\hline $\mathrm{PdCl}_{2} \mathrm{DPPM}$ & 5.0 & n.d. & n.d. & n.d. & n.d. & 95 & n.d. \\
\hline $\mathrm{PdCl}_{2} \mathrm{DPPE}$ & 12.5 & 0.2 & n.d. & 2.8 & n.d. & 97 & n.d. \\
\hline $\mathrm{PdCl}_{2} \mathrm{DPPP}$ & 83.9 & 0.2 & 0.8 & 45 & Traces & 50 & 4.0 \\
\hline $\mathrm{PdCl}_{2} \mathrm{DPPB}$ & 98.2 & 3.5 & 0.8 & 35 & 0.2 & 15 & 45.5 \\
\hline $\mathrm{PdCl}_{2} \mathrm{DPPF}$ & 90.0 & n.d. & Traces & 0.9 & n.d. & 0.6 & 98.5 \\
\hline $\mathrm{PdCl}_{2}$ DPEphos & 5 & n.d. & Traces & 20.8 & 38.5 & 40.7 & Traces \\
\hline $\mathrm{PdCl}_{2} \mathrm{X}$ anphos & 2 & n.d. & Traces & Traces & Traces & Traces & Traces \\
\hline
\end{tabular}

Run conditions: $\left[\mathrm{PdCl}_{2}(\mathrm{P}-\mathrm{P})\right]=6.8 \times 10^{-3} \mathrm{mmol} ;$ nitrobenzene $=0.50 \mathrm{mmol}(61.56 \mathrm{mg}) ;$ solvent $=20 \mathrm{~mL}(\mathrm{AcOH}=35 \mathrm{molar} \%$ in methanol); $\mathrm{CO}=4.5 \mathrm{MPa}, \mathrm{T}=100{ }^{\circ} \mathrm{C}$; reaction time $=5 \mathrm{~h}$.

${ }^{a}$ Evaluated by GC analysis as ( $m o l$ of nitrobenzene converted/initial mol of nitrobenzene) 100 .

${ }^{\mathrm{b}}$ Evaluated by HPLC analysis; n.d. = not detected; A, B, C, D, E, DPU see notes in Scheme 2.

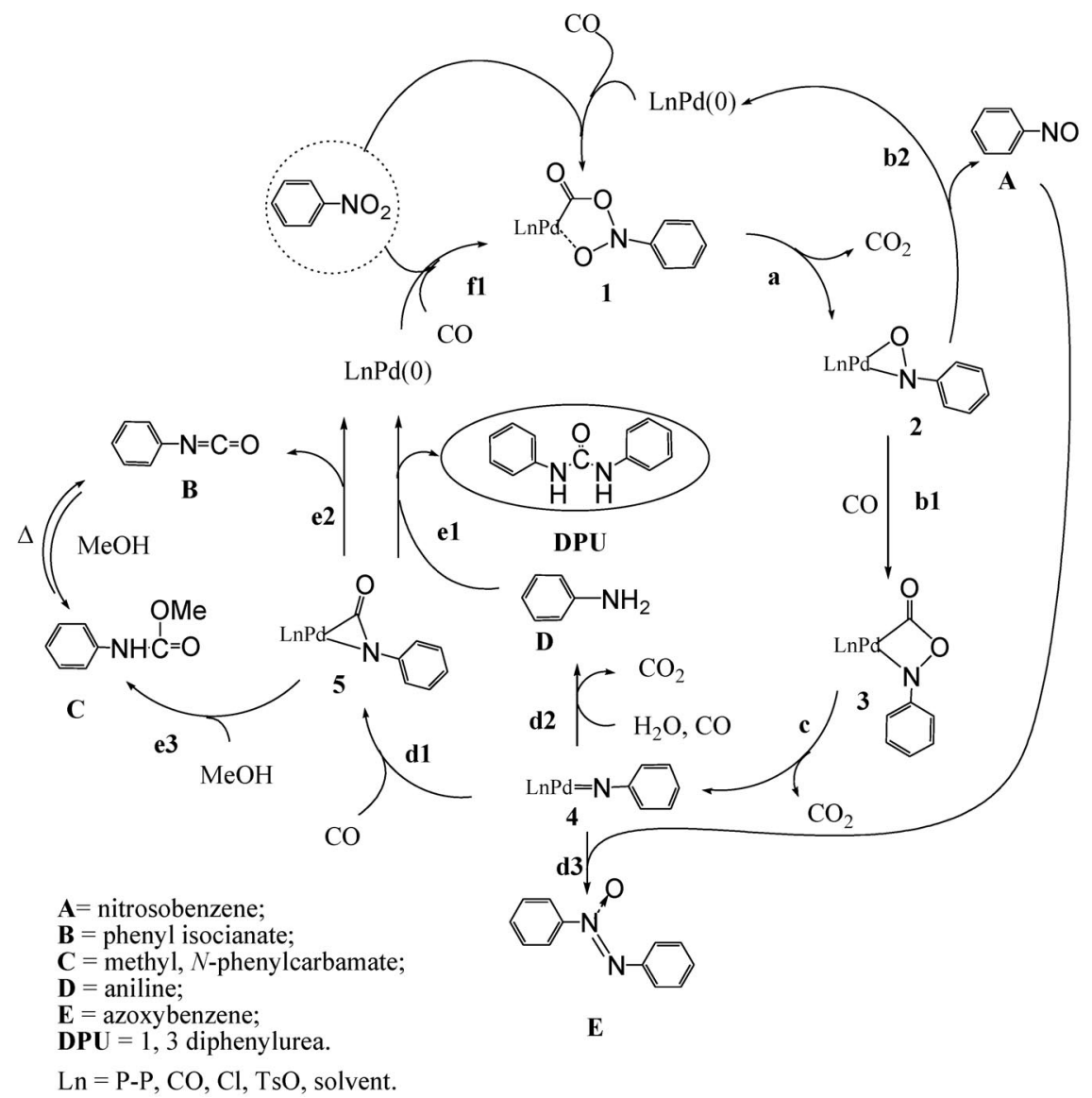

Scheme 2 Simplified reaction mechanism proposed for the reductive carbonylation of nitrobenzene.

(C) 2012, IUPAC

Pure Appl. Chem., Vol. 84, No. 3, pp. 473-484, 2012 
Among the catalysts proposed, $\mathrm{PdCl}_{2}(\mathrm{DPPE}), \mathrm{PdCl}_{2}(\mathrm{DPPP}), \mathrm{PdCl}_{2}(\mathrm{DPPB})$, and $\mathrm{PdCl}_{2}(\mathrm{DPPF})$ show the highest activity (in terms of nitrobenzene conversion), whereas $\mathrm{PdCl}_{2}(\mathrm{DPPM})$, $\mathrm{PdCl}_{2}$ (DPEphos), and $\mathrm{PdCl}_{2}$ (XANphos) have a very poor catalytic activity. By the analysis of the products distribution, the influence on the selectivity of the nature of the diphosphine ligands is notable.

The difference in catalytic behavior induced by the various P-P ligands can be largely explained by steric reasoning, assuming that the stabilization of the $\operatorname{Pd}(0)$ intermediates and the reoxidation to $\operatorname{Pd}(\mathrm{II})$ compounds are crucial points in the mechanism generally accepted, based on the steps depicted in Scheme 1 [29,46-51,59-63]. Initially, in the presence of $\mathrm{CO}$ and of the catalyst, the nitro compound generates a metallacycle 1 [26-30,64]. This intermediate undergoes decarboxylation, leaving the nitroso group $\mathbf{2}$ bonds to the metal. The subsequent insertion of $\mathrm{CO}$ gives intermediate $\mathbf{3}$, and the followed decarboxylation gives a nitrene species $\mathbf{4}$ as key intermediate. In the presence of $\mathrm{CO}$ and $\mathrm{H}_{2} \mathrm{O}$, aniline forms together the $\operatorname{Pd}(0)$ species, which restarts the catalytic cycle.

The nitrene species $\mathbf{4}$ can either react with CO to give isocyanates (steps IVc and Vb), which reacts further with methanol (or water) to give methyl, $N$-phenylcarbamate, or can also react with a nitroso compound or another nitrene intermediate, yielding $N, N^{\prime}$-azoxybenzene or $N, N^{\prime}$-azobenzene (not included in Scheme 1).

The nitrene species $\mathbf{4}$ in turn can be carbonylated to form phenylisocyanate complex $\mathbf{5}$. Complex 5 reacts with newly formed aniline to give the desired DPU and the Pd(0) species, which restarts the cycle.

The formation of nitrosobenzene, $N, N^{\prime}$-azoxybenzene, aniline, methyl $N$-phenylcarbamate, or phenylisocianate produces also $\mathrm{Pd}(0)$ species, which further react with $\mathrm{CO}$ and nitrobenzene (such reaction might also be proton-assisted [26-30]). The Pd(II) species 1 formed can restart the catalytic cycle.

Since the selectivity depends on the relative stability of intermediates 1-5 and the activity of the relative stability of $\mathrm{Pd}(\mathrm{II})$ and $\mathrm{Pd}(0)$ species, the electronic and steric characteristics of the P-P ligands play a key role in the optimization of catalyst performances. Whereas $\mathrm{Pd}(\mathrm{II})$ is known to distinctly favor a square planar configuration, $\operatorname{Pd}(0)$ prefers a Y-shaped or tetrahedral rearrangement $[26,46]$. The ideal bite angle in a square planar rearrangement has a value of $90^{\circ}$, while the tetrahedral configuration requires a larger angle of $109.5^{\circ}$. Theoretical calculations have shown that the lowest energies for these Y-shaped compounds are obtained at P-Pd-P angles between $94^{\circ}$ and $102^{\circ}[58,65]$. In Table 3 are reported the theoretical $\mathrm{P}-\mathrm{Pd}-\mathrm{P}$ angles of the complexes considered in the present paper, which led to the more interesting results.

Table $3 \mathrm{P}-\mathrm{Pd}-\mathrm{P}$ angles in various $\mathrm{Pd}(\mathrm{P}-\mathrm{P}) \mathrm{Cl}_{2}$ complexes.

\begin{tabular}{lcc}
\hline Complex & $\begin{array}{c}\text { P-Pd-P } \\
\text { deg. }\end{array}$ & Ref. \\
\hline $\mathrm{PdCl}_{2} \mathrm{DPPM}$ & 72.7 & {$[65]$} \\
$\mathrm{PdCl}_{2} \mathrm{DPPE}$ & 85.8 & {$[65]$} \\
$\mathrm{PdCl}_{2} \mathrm{DPPP}$ & 90.6 & {$[65]$} \\
$\mathrm{PdCl}_{2} \mathrm{DPPF}$ & 96.1 & {$[65]$} \\
$\mathrm{PdCl}_{2} \mathrm{DPPB}$ & 98.1 & {$[66]$} \\
\hline
\end{tabular}

According to the discussion, DPPM has a bite angle too small to yield highly stable $\operatorname{Pd}(0)$ species, thus the $\mathrm{PdCl}_{2}$ (DPPM) leads to poor nitrobenzene conversion (10 molar \%) and forms Pd metal at the end of reaction. $N, N^{\prime}$-azoxybenzene is found as the main product and aniline as byproduct ( 5 molar \%), whereas DPU, phenylisocianate, and methyl $N$-phenyl carbamate are not detected.

At the same way, $\mathrm{PdCl}_{2} \mathrm{DPPE}$ complex leads to a conversion of 12.5 molar \% with selectivity to $N, N^{\prime}$-azoxybenzene of 97.0 molar \%. This high selectivity, together with the formation of aniline as byproduct, suggests that with this ligand the intermediate $\mathbf{4}$ is stable enough but both the nucleophilic 
attack of nitrosobenzene, formed in step II, and the reaction with $\mathrm{H}_{2} \mathrm{O}-\mathrm{CO}$ are favored with respect to the $\mathrm{CO}$ insertion into the $\mathrm{Pd}=\mathrm{N}$ bond to give 5 .

With DPPP, however, the conversion of $\operatorname{Pd}(\mathrm{II})$ into $\operatorname{Pd}(0)$ and vice versa appears to proceed smoothly. The conversion was ca. 84 molar $\%$ with formation of $N, N^{\prime}$-azoxybenzene ( 50 molar $\%$ ), aniline (35 molar \%), and DPU (3 molar \%). The stability of $\mathrm{Pd}(0)$ intermediate avoids the reduction to $\mathrm{Pd}$ metal and permits an easy reoxidation to species 1 . Nitrobenzene conversion is high even if $N, N^{\prime}$-azoxybenzene and aniline are the main products and DPU, nitrosobenzene, phenylisocianate, and methyl $\mathrm{N}$-phenyl carbamate are the byproducts. The formation of these byproducts in detectable amount, however, accords with the increased stability of the intermediate $\mathbf{4}$ and a probable effect of the ligand on the rate of $\mathrm{CO}$ insertion to give intermediate 5, according with the $\mathrm{P}-\mathrm{Pd}-\mathrm{P}$ angle higher than $90^{\circ}$.

Larger ligands like DPPB and DPPF (P-Pd-P angle $98.1^{\circ}$ and $96.1^{\circ}$, respectively) become more suitable for $\operatorname{Pd}(0)$ complexes than for the $\mathrm{Pd}(\mathrm{II})$ counterparts. According to this the conversion is very high (98.2 and 90 molar \%, respectively). Further studies have pointed out that all the reactions could reach complete conversion at prolonged reaction times, suggesting that the catalyst is not deactivated by the formation of Pd metal. As a matter of fact, we have found that the reaction proceeds with a zeroorder reaction rate with respect to nitrobenzene without showing any rate decrease owing to possible decomposition of the catalytic system (Fig. 2).

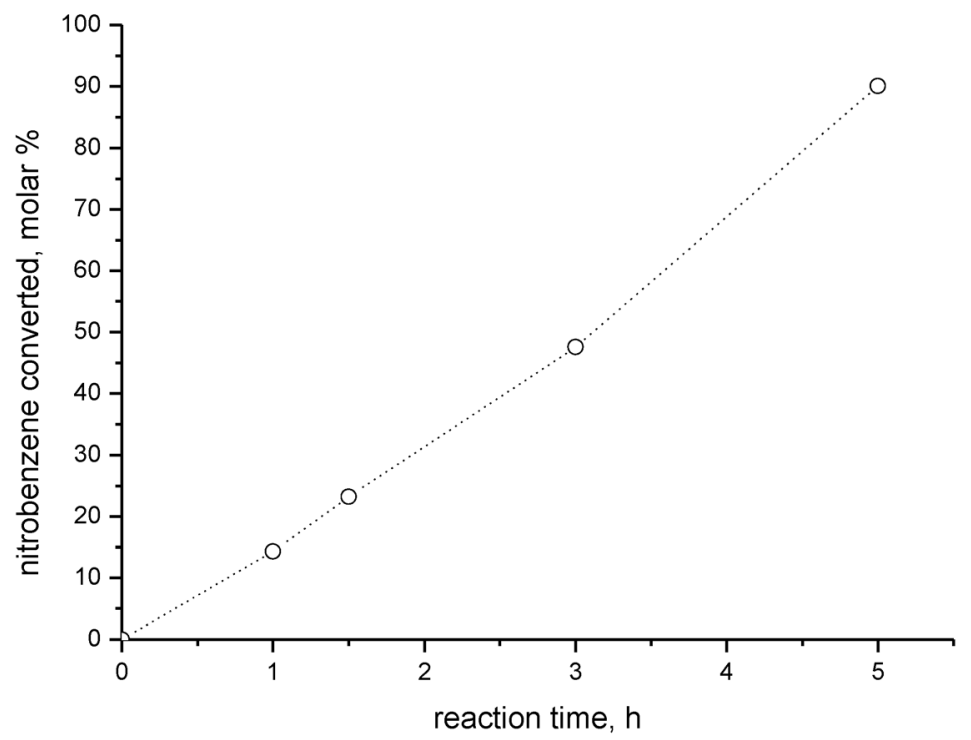

Fig. 2 Conversion of nitrobenzene vs. reaction time. Run conditions: $\left[\mathrm{PdCl}_{2}(\mathrm{DPPF})\right]=6.8 \times 10^{-3} \mathrm{mmol}$; nitrobenzene $=0.50 \mathrm{mmol}(61.56 \mathrm{mg}) ;$ solvent $=20 \mathrm{~mL}(\mathrm{AcOH}=35$ molar $\%$ in methanol $) ; \mathrm{CO}=4.5 \mathrm{MPa}, T=$ $100{ }^{\circ} \mathrm{C}$.

In both cases, the selectivity to DPU increases while the amount of $N, N^{\prime}$-azoxybenzene decreases. In literature, the $\mathrm{Pd}(\mathrm{OAc})_{2} / \mathrm{Ph}_{2} \mathrm{P}\left(\mathrm{CH}_{2}\right)_{n}-\mathrm{PPh}_{2} / \mathrm{NEt}_{4} \mathrm{Cl}(n=1-6)$ catalyst systems have been used for the production of DPU from nitrobenzene, aniline, and $\mathrm{CO}$, finding a maximum catalytic activity for the DPPB ligand $(n=4)$. A mechanism has also been proposed that could explain why the larger and more flexible DPPB and DPPF ligands are effective in the urea synthesis [29,67].

Table 2 shows that the DPPF leads to a higher selectivity to DPU (98.5 molar \%) with respect to the DPPB ligand (45.5 molar \%), although the conversion is slightly lower (90 molar \%). We can suppose that such an increase of DPU selectivity is a consequence of a probable increase of the aniline formation. It is plausible that under the influence of an acidic cocatalyst, the reaction like step $\mathbf{d} \mathbf{2}$ occurs 
at the expense of step $\mathbf{d 3}$, thus suppressing the formation of azoxybenzene. Step $\mathbf{d} \mathbf{1}$ would probably be less influenced by the acid due to the large excess of $\mathrm{CO}$ in methanol. As a result, the enlarged aniline production would be favored, expressed either in a high formation of a large amount of the urea derivative.

The catalysis carried out with $\mathrm{PdCl}_{2}$ (DPEphos) and $\mathrm{PdCl}_{2}$ (XANphos) precursors lead low nitrobenzene conversion (less than 10 molar $\%$, in $5 \mathrm{~h}$ ), yielding as major products $N, N^{\prime}$-azoxybenzene and aniline. The large bite angles P-Pd-P (higher than 100), which go along with decreased electron density on the metal, make the reductive elimination easier from the $\mathrm{Pd}(\mathrm{II})$ intermediates. This favors the products formation but forms also inactive $\operatorname{Pd}(0)$ intermediates. The reoxidation of such $\operatorname{Pd}(0)$ species, to reform the active $\operatorname{Pd}(\mathrm{II})$ intermediate $\mathbf{1}$, becomes more difficult. Therefore, it is plausible that such reoxidation becomes the rate-determining step of the process, in accord with the low conversion obtained in $5 \mathrm{~h}$. Since at the end of such reaction we have also found Pd metal, we can suppose that the $\operatorname{Pd}(0)$ intermediates decompose faster to Pd metal with respect to their reoxidation to the $\mathrm{Pd}(\mathrm{II})$ species 1.

\section{Influence of strongly and weakly coordinating ligands on catalytic activity and selectivity}

Since it is reported that for Pd(II) complexes having monodentate phosphine ligands, the addition of chloride anions has a positive effect on the selectivity to DPU [25], whereas in the presence of chelating diphosphines an inhibiting effect is observed [29], we get an insight also into the influence on the selectivity of the coordinating anions. In this regard, we compared the catalytic activity and selectivity of the complexes of $\mathrm{PdCl}_{2} \mathrm{DPPF}$ and $\mathrm{PdCl}_{2} \mathrm{DPPB}$ with the Pd(TsO) $)_{2} \mathrm{DPPF}$ and $\mathrm{Pd}(\mathrm{TsO})_{2} \mathrm{DPPB}$ complexes, having the strongly coordinating $\mathrm{Cl}$ and the weakly coordinating $\mathrm{TsO}$ ( $p$-toluenesulfonate anion), respectively.

Table 4 shows the results obtained.

Table 4 Influence on catalytic activity and selectivity of strongly and weakly coordinating ligands.

\begin{tabular}{lccccccc}
\hline $\begin{array}{l}\text { Catalyst } \\
\text { precursor }\end{array}$ & $\begin{array}{c}\text { Conversion } \\
\text { molar } \%\end{array}$ & \multicolumn{6}{c}{ Selectivity, molar \% } \\
\cline { 3 - 8 } & & $\mathbf{A}$ & $\mathbf{B}$ & $\mathbf{C}$ & $\mathbf{D}$ & $\mathbf{E}$ & $\mathbf{D P U}$ \\
\hline $\mathrm{PdCl}{ }_{2} \mathrm{DPPB}$ & 98.2 & 3.5 & 0.8 & 35 & 0.2 & 15 & 45.5 \\
$\mathrm{Pd}(\mathrm{TsO})_{2} \mathrm{DPPB}$ & 97.5 & Traces & 0.6 & 28,6 & 0.3 & 5,5 & 65.0 \\
$\mathrm{PdCl}{ }_{2} \mathrm{DPPF}$ & 90.0 & n.d. & Traces & 0.9 & n.d. & 0.6 & 98.5 \\
$\mathrm{Pd}(\mathrm{TsO})_{2} \mathrm{DPPF}$ & 91.0 & n.d. & Traces & 0.3 & n.d. & 0.2 & 99.5 \\
\hline
\end{tabular}

Run conditions: $\left[\mathrm{PdX}_{2}(\mathrm{P}-\mathrm{P})\right]=6.8 \times 10^{-3} \mathrm{mmol}(\mathrm{X}=\mathrm{Cl}$, TsO; $\mathrm{P}-\mathrm{P}=\mathrm{DPPB}, \mathrm{DPPF})$; nitrobenzene = $0.50 \mathrm{mmol}(61.56 \mathrm{mg})$; solvent $=20 \mathrm{~mL}(\mathrm{AcOH}=35 \mathrm{molar} \%$ in methanol $) ; \mathrm{CO}=4.5 \mathrm{MPa}, T=$ $100{ }^{\circ} \mathrm{C}$, reaction time $=5 \mathrm{~h} ;$ n.d. $=$ not detected

It can be pointed out that the nitrobenzene conversion is not affected by the nature of the anionic ligands (98.2-97.5 molar \% for DPPB and 90-91 molar \% for DPPF), even if it affects the selectivity. As matter of fact, weakly coordinating ligands favor the DPU formation (the selectivity of DPPB/DPPF increases from $45 / 98.5$ molar \% with $\mathrm{Cl}$ up to $65 / 99.5$ molar \% with $\mathrm{TsO}$ ) at the expenses of $N, N^{\prime}$-azoxybenzene and aniline. Owing to the coordinating properties of chloride anions, the palladium center will be better stabilized but also less readily available for the reacting substrates. According to the proposed reaction mechanism, it is plausible that the $\mathrm{Cl}$ ligand slows steps $\mathbf{d} \mathbf{1}$ and $\mathbf{d} \mathbf{2}$ as a result of the competition of $\mathrm{Cl}$ with $\mathrm{CO}$ for coordination to the metal. This favors the nucleophilic attack of aniline to the Pd-azide intermediate $\mathbf{4}$ with respect to the migratory insertion of $\mathrm{CO}$, which is the key step in the DPU formation. 


\section{CONCLUSION}

The activity and the selectivity of the $\mathrm{Pd}(\mathrm{II})-(\mathrm{P}-\mathrm{P})$ precursors in the reductive carbonylation of nitrobenzene mainly depend on the bite angle of the $\mathrm{P}-\mathrm{P}$ ligand but can also be influenced by the nature of the solvent and of the other coordinating ligands. We have found that by using $\mathrm{AcOH}$ in large excess as a promoter/cosolvent you get the highest selectivity to DPU.

Among the catalyst precursors tested, $\mathrm{PdCl}_{2} \mathrm{DPPB}$ and $\mathrm{PdCl}_{2} \mathrm{DPPF}$ complexes give the best conversion of nitrobenzene, 98.2 and 90.0 molar $\%$ respectively (in $5 \mathrm{~h}$ at $100{ }^{\circ} \mathrm{C}, 4.5 \mathrm{MPa}, \mathrm{AcOH}$ 35 molar \% in methanol). The highest selectivity to DPU has been obtained, however, with the $\mathrm{PdCl}_{2}$ DPPF complex (98.5 molar \%).

Furthermore, we have found that both the activity and selectivity are affected by the coordinating nature of the anionic ligands. The conversion and the selectivity to DPU further increase by using weakly instead of strongly coordinating ligands. The best results are obtained with the $\mathrm{Pd}(\mathrm{TsO})_{2} \mathrm{DPPF}$ complex, which leads to a conversion of 91.0 molar \% with a selectivity of 99.5 molar \% to DPU.

\section{REFERENCES}

1. T. P. Vishnyakova, I. A. Golubeva, E. V. Glebova. Russ. Chem. Rev. (Engl. Transl.) 54, 249 (1985).

2. W. A. Skinner, H. T. Crawford, L. C. Rutledge, M. A. Moussa. J. Pharm. Sci. 68, 391 (1979).

3. R. M. Nieto, A. Coelho, A. Martinez, A. Stefanachi, E. Sotelo, E. Ravina. Chem. Pharm. Bull. 51, 1025 (2003).

4. E. Mounetou, J. Legault, J. Lacroix, R. C. Gaudreault. J. Med. Chem. 46, 5055 (2003).

5. P. V. G. Reddy, C. S. Reddy, C. N. Raju. Chem. Pharm. Bull. 51, 860 (2003).

6. M. Kumar, M. V. Hosur. Eur. J. Biochem. 270, 1231 (2003).

7. A. Ricci, A. Carra, E. Rolli C. Bertoletti, G. Morini, M. Incerti, P. Vicini. J. Plant. Growth Regul. 23, 207 (2004).

8. M. Srinivasan, V. Nachiappan, R. Rajasekharan. J. Biosci. 31, 599 (2006).

9. A. G. M. Barrett, M. J. Betts, A. Fenwick. J. Org. Chem. 50, 169 (1985).

10. E. T. Shawl, H. S. Kesling. U.S. Patent 4,871,871 (1989).

11. R. T. Wheelhouse, D. E. V. Wilman, W. Thomson, M. F. G. Svevens. J. Chem. Soc., Perkin Trans. 1249 (1995).

12. Y. Wang, R. T. Wheelhouse, L. Zhao, D. A. F. Langnel, M. F. G. Stevens. J. Chem. Soc., Perkin Trans. 11669 (1998).

13. H. S. Kim, Y. J. Kim, H. Lee, S. D. Lee, C. S. Chin. J. Catal. 184, 526 (1999).

14. S. P. Gupte, A. B. Shivarkar, R. V. Chaudhari. Chem. Commun. 2620 (2001).

15. H. Yoshida, E. Shirakawa, Y. Honda, T. Hiyama. Angew. Chem., Int. Ed. 41, 3247 (2002).

16. J. M. Humphrey, Y. S. Liao, A. Ali, T. Rein, Y. L. Wong, H. J. Chen, A. K. Courtney, S. F. Martin. J. Am. Chem. Soc. 124, 8584 (2002).

17. J. J. Yin, S. L. Buchwald. J. Am. Chem. Soc. 124, 6043 (2002).

18. K. C. Nicolaou, P. S. Baran, Y. L. Zhong, K. Sugita. J. Am. Chem. Soc. 124, 2212 (2002).

19. J. R. Dunetz, R. L. Danheiser. Org. Lett. 5, 4011 (2003).

20. A. G. Sergeev, G. A. Artamkina, I. P. Beletskaya. Tetrahedron Lett. 44, 4719 (2003).

21. G. G. Muccioli, J. Wouters, J. H. Poupaert, B. Norberg, W. Poppitz, G. K. E. Scriba, D. M. Lambert. Org. Lett. 5, 3599 (2003).

22. S. H. Lee, B. Clapham, G. Koch, J. Zimmermann, K. D. Janda. Org. Lett. 5, 511 (2003).

23. H. J. Twitchett. Chem. Soc. Rev. 3, 209 (1974).

24. J. S. Oh, S. M. Lee, J. K. Yeo, C. W. Lee, J. S. Lee. Ind. Eng. Chem. Res. 30, 1456 (1991).

25. J. E. Alessio, G. Mestroni. J. Organomet. Chem. 291, 117 (1985). 
26. S. Cenini, F. Ragaini. Catalytic Reductive Carbonylation of Organic Nitro Compounds, Kluwer, Dordrecht (1996).

27. A. M. Tafesh, J. Weiguny. Chem. Rev. 96, 2035 (1996).

28. F. Ragaini, S. Cenini. J. Mol. Catal., A: Chem. 109, 1 (1996).

29. P. Wehman, H. M. A. van Donge, A. Hagos, P. C. J. Kamer, P. W. N. M. van Leeuwen. J. Organomet. Chem. 535, 183 (1997).

30. F. Ragaini. Dalton Trans. 6251 (2009).

31. P. Giannoccaro. J. Organomet. Chem. 336, 271 (1987).

32. P. Giannoccaro. Inorg. Chim. Acta 142, 81 (1988).

33. F. Bigi, R. Maggi, G. Sartori. Green Chem. 2, 140 (2000).

34. I. Maya, O. Lopez, S. Maza, J. G. Fernandez-Bolanos, J. Fuentes. Tetrahedron Lett. 44, 8539 (2003).

35. L. Lemoucheux, J. Rouden, M. Ibazizene, F. Sobrio, M. C. Lasne. J. Org. Chem. 68, 7289 (2003).

36. R. Ballini, D. Fiorini, R. Maggi, P. Righi, G. Sartori, R. Sartorio. Green Chem. 5, 396 (2003).

37. G. Yang, Z. X. Chen, H. Q. Zhang. Green Chem. 5, 441 (2003).

38. P. V. G. Reddy, Y. H. Babu, C. S. Reddy. J. Heterocycl. Chem. 40, 535 (2003).

39. R. V. Hoffman, S. Madan. J. Org. Chem. 68, 4876 (2003).

40. A. S. Ripka, D. D. Diaz, K. B. Sharpless, M. G. Finn. Org. Lett. 5, 1531 (2003).

41. F. Paul. Coord. Chem. Rev. 203, 269 (2000).

42. F. Ragaini, A. Ghitti, S. Cenini. Organometallics 18, 4925 (1999).

43. F. Ragaini, S. Cenini. J. Mol. Catal., A: Chem. 161, 31 (2000).

44. E. Bolzacchini, R. Lucini, S. Meinardi, M. Orlandi, B. Rindone. J. Mol. Catal. A: Chem. 110, 227 (1996).

45. V. Macho, M. Kralik, F. Halmo. J. Mol. Catal., A: Chem. 109, 119 (1996).

46. P. Wehman, L. Borst, P. C. J. Kamer, P. W. N. M. van Leeuwen. J. Mol. Catal., A: Chem. 112, 23 (1996).

47. P. Wehman, P. C. J. Kamer, P. W. N. M. van Leeuwen. Chem. Commun. 217 (1996).

48. G. Ling, J. Z. Chen, S. W. Lu. J. Mol. Catal., A: Chem. 202, 23 (2003).

49. Y. Ya, S. Lu. Tetrahedron Lett. 40, 4845 (1999).

50. P. Wehman, G. C. Dol, E. R. Moorman, P. C. J. Kamer, P. W. N. M. van Leeuwen, J. Fraanje, K. Goubitz. Organometallics 13, 4856 (1994).

51. P. Wehman, V. E. Kaasjager, W. G. J. de Lange, F. Hartl, P. C. J. Kamer, P. W. N. M. van Leeuwen, J. Fraanje, K. Goubitz. Organometallics 14, 3751 (1995).

52. J. S. Lee, C. W. Lee, S. M. Lee, K. H. Park. J. Mol. Catal. 61, L15 (1990).

53. C. W. Lee, J. S. Lee, S. M. Lee, K. D. Kim, N. S. Cho, J. S. Oh. J. Mol. Catal. 81, 17 (1993).

54. A. Vavasori, G. Cavinato, L. Toniolo. J. Mol. Catal., A: Chem. 176, 11 (2001).

55. A. Vavasori, G. Cavinato, L. Toniolo. J. Mol. Catal., A: Chem. 191, 209 (2003).

56. A. Vavasori, L. Toniolo, G. Cavinato, F. Visentin. J. Mol. Catal., A: Chem. 204-205, 295 (2003).

57. C. Bianchini, A. Meli, W. Oberhauser, A. M. Segarra, C. Claver, E. J. Garcia Suarez. J. Mol. Catal., A: Chem. 265, 292 (2007).

58. P. Dierkes, P. W. N. M. van Leeuwen. J. Chem. Soc., Dalton Trans. 1519 (1999).

59. C. W. Lee, S. M. Lee, J. S. Oh. Ind. Eng. Chem. Res. 30, 1456 (1991).

60. S. M. Lee, N. S. Cho, K. D. Kim, J. S. Oh, C. W. Lee, J. S. Lee. J. Mol. Catal. 73, 43 (1992).

61. S. Cenini, C. Crotti. Metal Promoted Selectivity in Organic Synthesis, Kluwer, Dordrecht (1991).

62. F. Ragaini, M. Gasperini, S. Cenini, L. Arnera, A. Caselli, P. Macchi, N. Casati. Chem.-Eur. J. 15, 8064 (2009).

63. R. Ugo, R. Psaro, M. Pizzotti, P. Nardi, C. Dossi, A. Andreetta, G. Capparella. J. Organomet. Chem. 417, 211 (1991).

64. A. Sessanta, B. Milani, G. Mestroni, E. Zangrando, L. Randaccio. J. Organomet. Chem. 545-546, 89 (1997). 
65. W. J. van Zeist, R. Visser, F. M. Bickelhaupt. Chem.-Eur. J. 15, 6112 (2009).

66. W. L. Steffen, G. J. Palenik. Inorg. Chem. 15, 2432 (1976).

67. C. W. Lee, S. M. Lee, J. S. Oh, J. S. Lee. Catal. Lett. 19, 217 (1993). 